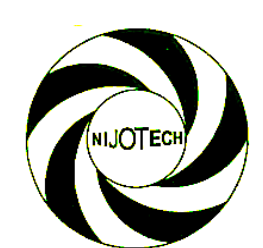

Nigerian Journal of Technology (NIJOTECH)

Vol. 38, No. 2, April 2019, pp. $302-310$

Copyright@ Faculty of Engineering, University of Nigeria, Nsukka,

Print ISSN: 0331-8443, Electronic ISSN: 2467-8821 www.nijotech.com

http://dx.doi.org/10.4314/njt.v38i2.5

\title{
DETERMINED UNCERTAINTY MODELS OF REFERENCE MATERIAL PROPERTIES AND THE EN 338 STRENGTH CLASS OF NIGERIAN GROWN TERMINALIA IVORENSIS(BLACK AFARA) TIMBER
}

\author{
A. I. Mohammed ${ }^{1, *}$, S. P. Ejeh ${ }^{2}$, Y. D. Amartey ${ }^{3}$ and A. Ocholi ${ }^{4}$ \\ 1, Julius Berger Nigeria PlC, 10 Shettima Munguno CresCEnt, Utako, ABUja FCT, NIGERIA \\ 2, 3, 4, Department of Civil Engineering, AhMAdu Bello University, Zaria, KadunA STATE. NIGERIA \\ E-mail addresses: ${ }^{1}$ ismaila.amodu@julius-berger.com, ${ }^{2}$ engrdrspejeh@yahoo.com, \\ 3dadaamartey@yahoo.co.uk, ${ }^{4}$ amanaocholi@yahoo.com
}

\begin{abstract}
The purpose of this paper was the determination of the uncertainty models of reference material properties and [1] strength class of Nigerian Grown Terminalia ivorensis timber, so that it can be used in structures designed based on the Eurocode 5. The test data were analysed using Easyfit $\mathbb{B}$ statistical package. The uncertainty models (Coefficients of Variation and Distribution models) of the reference material properties (density, bending strength and modulus of elasticity) were determined. The coefficient of variation of the density, modulus of elasticity and bending strength were found to be $15 \%, 21 \%$ and $16 \%$ respectively. The mean values of the density, modulus of elasticity and the bending strengths were determined at moisture contents of $17.93 \%$. The values were adjusted to $12 \%$ moisture content for the determination of the strength class according to [1]. Five standard probability distribution models (Normal, Lognormal, Gumbel, Weibull and Frechet) were fitted to each of the three reference material properties using Kolmogorov Smirnov probability distribution fitting technique. The best fit theoretical distribution models were found to be Normal distribution for Density, Lognormal distribution for Modulus of Elasticity and Weibull for Bending Strength. The Terminalia ivorensis timber specie was also classified as D18 in accordance with [1] specification. The uncertainty models will facilitate the application of reliability based approach in the design of timber structures with Terminalia ivorensis. Also Terminalia ivorensis can now be used for construction of structural timber designed based on Eurocode 5 since its strength class is now established.
\end{abstract}

Keywords:Black Afara Timber, Terminalia Ivorensis, Uncertainty Models, Density, Modulus of Elasticity

\subsection{Introduction}

Recently, the use of timber structures has increased in the construction industry due to attributed advantages such as environmentally friendly nature of timber, fully renewable potential and low handling costs [2]. Timber is widely available natural resources throughout the world, which with properly managed wood plantation, there is potential for continuous and sustainable supply of raw timber materials. In addition, it exhibits unique material properties; it is a light weight material and, compared to its weight, the strength is high; the strength/weight ratio is even higher than for steel that is why it is used widely as a structural material for roofing system and pedestrian or bicycle bridges. Also it has low modulus of elasticity compared to concrete and steel [3], this implies low stiffness capacity and consequent poor resistance to deflection in service. The mentioned attributes among others, gave rise to the acceptance of timber worldwide as building material that can compete stiffly with the conventional/popular concrete and steel in the arena of the building industry with considerable advantages of low embodied energy, low carbon impact, and sustainability.

* Corresponding author, tel: +234-803-313-9280 
The current Nigerian Code of Practice for design of timber structures in Nigeria [4] is based on permissible stress method based on [5] that was withdrawn in the late 70s and replaced with [6]. The [6] itself passed through several revisions and completely withdrawn since March, 2010. This implied that [6] would never be update. The implication is that the [4] is now left without basis for further revision. To design timber structures in Nigeria in line with the current global best practices for timber structural design, our design criteria must therefore be shifted to the most recent approach.

Since design of Engineering structures in Nigeria are generally based on the British standards, and the current British standard for design of timber structures is the [7] which is based on the limit state design philosophy, there is therefore the need to adopt the [7] in Nigeria. The use of a particular timber species for design of timber structures according to [7], requires determination of its appropriate [1] strength class. Likewise, to further accommodate uncertainties in material properties in the design of timber structures, there is therefore the need to establish their statistical properties (Mean, Standard Deviation, Coefficient of Variation and the appropriate theoretical distribution model).

Timber is an efficient building material, not only in regard to its mechanical properties but also because it is a highly sustainable material. It is considered a sustainable building material because it is derived from a renewable source and has a low embodied energy [8-10]. Embodied energy reflects the minimal nonrenewable energy used in the production of timber and its application in construction. It has sound thermal properties, meaning that timber structures rely less on carbon-emitting heating and cooling appliances than building construction of other material. Wood is also durable, since many products, particularly hardwoods have a service life of greater than 50 years, and often require little energy in maintenance [10]. Wood can also be recycled, which is important in terms of storing carbon through the life of a product and its transformation. Wood is inexpensive material. Forest is a wood factory which produces wood using only solar energy [11].

Timber is a widely available natural resource in many countries; with proper management, there is a potential for a continuous and sustainable supply of raw timber material in the future. Due to the low energy use and the low level of pollution associated with the manufacturing of timber structures, the environmental impact of timber structures is much smaller than for structures built using other building materials [9].

Timber is an advantageous building material. Its strength is high; the strength to weight ratio is even higher than for steel $[3,9]$. However, timber is still not utilized to its full potential in the building and construction sector considering its beneficial properties. Attributes such as high performance in regard to reliability, serviceability and durability are generally not associated with timber as a building material. One of the main reasons for this is that timber is a highly complex material; it actually requires a significant amount of expertise to fully appreciate the potential of timber as a structural building material.

Timber is defined as wood that is only used for engineering purposes. The vast use of timber in construction industry in Nigeria, especially for roof trusses, could be linked to its abundance all over the country. It is not only found in almost everywhere but also very cheap. It is one of the cheapest construction materials in the country [12].

In the past, stakeholders have constrained technical knowledge of the use of timber. This is as a result of the fact that technical building and engineering training/education has favored steel, concrete and masonry over the timber, as wood are often seen as an aesthetic material rather than engineering [13].

Recently, the interest in designing timber structures has steadily increased. The reason for this being an increased focus in society on sustainability and environmental aspects but also due to the positive effects of timber materials on the inner climate in residential buildings and excellent architectural possibilities [13]. Furthermore, timber has been found technically and economically competitive compared with steel and concrete as a building material for a broad range of building structures such as e.g. large span roof structures and residential buildings.

In order to gain a better understanding of the reason for the special behavior of wood and timber material, it is helpful to start thinking about where the wood and the timber are 'produced'; in the stem of a tree [14]. In spite of the aforementioned advantages, unfortunately the strong hygric dependence of basically all mechanical properties renders many innovative ideas futile. In addition, time-dependent phenomena like long-term visco-elastic creep [15-16] and mechano-sorption under changing environmental conditions [17-19] can accelerate degradation of 
stiffness and strength over the life-time of a structural wood component and result in the loss of capacity and consequently structural integrity even after being in use for decades.

Therefore, the objectives of this paper are as follows:

i. To determination of the statistics of the reference material properties; density, modulus of elasticity and bending strength of Terminalia ivorensis (black afara) timber specie tested in the laboratory according to [20]

ii. Fit the statistical properties in $\mathrm{i}$ above into various distribution models using Kolmogorov-Smirnov test in Easyfit statistical software package based on the hypothesis that each of Lognormal, Normal, Weibull, Gumbel and Frechet distribution could be used to model the reference material properties of timber.

iii. Determine the appropriate [1] strength class of the Terminalia ivorensis timber.

Terminalia Ivorensis is a large deciduous forest tree ranging in height from 15 to $46 \mathrm{~m}$. It is branchless for up to $30 \mathrm{~m}$ [21]. The tree is native to Cameroon, Cote D“voire, Ghana, Guinea Bissau, Liberia, Sierra Leone and Nigeria [22]. In Nigeria, Terminalia ivorensis is found in lowland rainfall zone. It is a specie that is widely distributed throughout the tropics [23].

\section{MATERIALS AND METHODS}

\subsection{Materials}

The material used in this study is Terminalia ivorensis (Black afara) timber, obtained from the Sabon Gari Zaria timber market (Zaria timber sheds). This specie was chosen to reflect the current trends in wood usage of timber in Nigeria. Terminalia ivorensis is used extensively as timber for many structural applications especially for roof truss fabrication.

\subsection{Methods}

The following section provides explanations on the test procedures, methods and specifications adopted in carrying out testing of Terminalia ivorensis in the study.

\subsubsection{Conditioning of the Timber Specimens}

The Terminalia ivorensis timber specimen were prepared for the various test and delivered at the structures and material laboratory of the Department of Civil Engineering, Ahmadu Bello University, Zaria, on $10^{\text {th }}$ January, 2014. After the delivery at the laboratory, the timber was conditioned to $(20 \pm 2){ }^{\circ} \mathrm{C}$ and $(65 \pm 5) \%$ relative humidity, prior to testing based on EN 384 (2004) specification. Testing commenced at the laboratory on $12^{\text {th }}$ April, 2015.

\subsubsection{Determination of Density and Moisture Content}

The test specimens for the density and moisture content tests were prepared as specified in EN 131831 (2002). Forty specimens of dimension $40 \mathrm{~mm} \times$ $40 \mathrm{~mm} \times 70 \mathrm{~mm}$ were prepared. The specimens were labelled A-1, A-2, A-3, A-4... A-40, for the density test, $\rho_{d}$ and B-1, B-2, B-3, B-4... B-40, for moisture content. According to EN 13183-1 (2002), the bulk and the dry densities of the timber specimens were determined using equations 1.0 and 2.0 respectively. The moisture contents were determined using equation 3 .

$$
\begin{aligned}
& \rho_{b}=\frac{m_{u}}{V} \\
& \rho_{d}=\frac{m_{0}}{V} \\
& m_{c}(\%)=\frac{m_{u}-m_{0}}{m_{0}} \times 100
\end{aligned}
$$

Where, $\rho_{b}$ is bulk density in $\mathrm{kg} / \mathrm{m}^{3}, m_{u}$ is the bulk mass in $\mathrm{kg}, \mathrm{V}$ is the volume of sample in $\mathrm{m}^{3}, \rho_{\mathrm{d}}$ is the dry density in $\mathrm{kg} / \mathrm{m}^{3}$ and $m_{0}$ is the oven dry mass in $\mathrm{kg}$.

\subsubsection{The Bending Test}

The determination of global modulus of elasticity of timber using four-point bending test, is based on the application of loading at the central third of the test piece. Local Modulus of Elasticity was first recommended in the previous edition of EN 408 [20]. This method for the determination of local modulus of elasticity do not give consistent and reliable results, because the determination of the MOE is based on measurement of a deflection over a relatively short span between the loading points. The deflections are small, often less than $1 \mathrm{~mm}$. Hence the method is sensitive to measurement errors. Such errors can be caused by twisting of the timber during the test. The bending test setup used in this study to facilitate the determination of the global elastic modulus according to [20] is shown in Figure 1.

The global modulus of elasticity and the bending strength are calculated using equations 4.0 and 5.0 respectively:

$$
\begin{gathered}
E_{m}=\frac{L^{3}\left(F_{2}-F_{1}\right)}{4.7 b h^{3}\left(w_{2}-w_{1}\right)}=\frac{L^{3} \Delta F}{4.7 b h^{3} \Delta w} \\
f_{m}=\frac{a F_{\max }}{2 W}
\end{gathered}
$$




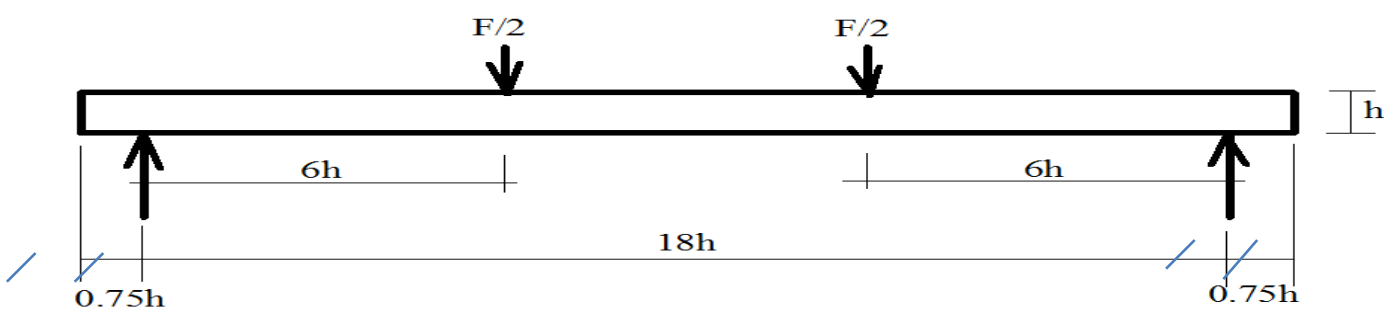

Figure 1: Four-point bending test set-up [20].

In (4) and (5), L is the centre to centre distance between supports in $\mathrm{mm}, \mathrm{b}$ is the width of the specimen in $\mathrm{mm}, \mathrm{h}$ is the depth of the specimen in $\mathrm{mm}, \mathrm{F}_{2}-\mathrm{F}_{1}$ is the load increment $(\Delta F)$ of load in $\mathrm{N}$. $\mathrm{W}_{2}-$ $\mathrm{W}_{1}$ is the corresponding deformation increment $(\Delta w)$ in $\mathrm{mm}$, $\mathrm{a}$ is the distance between any one support and the load that is closer to the support in $\mathrm{mm}, \mathrm{F}_{\max }$ is the failure load, and $\mathrm{W}$ is the section modulus of the specimen in $\mathrm{mm}^{3}$.

\section{RESULTS AND DISCUSSION}

The laboratory test results for the moisture content, density, bending strength and modulus of elasticity are presented in Table 1.0. The results were used as base line data for the determination of the uncertainty models of Terminalia Ivorensis timber. The uncertainty models (coefficient of variation and distribution models) as well as the strength classes are presented in the following sections.

\subsection{Moisture Content of the Terminalia Ivorensis}

The mean moisture contentment of the tested Terminalia ivorensis timber was found to be $17.93 \%$ with standard deviation and coefficient of variation of $5.31 \%$ and $29.5 \%$ respectively. Design of timber structures according to Eurocode 5 is achieved in conjunction with the [1] solid timber strength class, where all timber species having the same density, strength and stiffness properties are brought together under the same strength class. The [1] timber strength classes are based on timber reference moisture content of $12 \%$. This implies that, the $15.52 \%$ moisture content of the Terminalia ivorensis measure in this study is higher than the $12 \%$ reference moisture content.

Since the material properties of timber change with change in moisture content, the values of the material properties generated in the study will not agree with the values of strength, stiffness properties and density of timber given in [1]. In this research, the material properties of the Terminalia ivorensis were adjusted to $12 \%$ to conform to the standard.

\subsection{Density of Terminalia ivorensis}

Based on the density test conducted, the mean and coefficient of variation Terminalia ivorensis were found to be $449.24 \mathrm{~kg} / \mathrm{m}^{3}$ and $15.16 \%$ respectively. Kolmogorov Smirnov (KS) test of goodness of fit was performed using Easyfit statistical package to establish a suitable probability density for the density test data. Five distribution models, were fitted to the data, namely, Normal, Lognormal, Gumbel, Frechet and Weibull.

Normality tests were first conducted on the density test results. The coefficients of skewness and excess kurtosis were established based on the considered distribution models. It was established that the normal distribution has 0 skewness and 0 excess kurtosis (kurtosis equal to 3) as expected. The Weibull distribution is negatively skewed to the left, with skewness values of -0.517 (moderately skewed) and excess kurtosis of 0.293 (Platykurtic). The lognormal distribution is positively skewed with Skewness of 0.485 (approximately symmetric) and excess kurtosis of 0.387 (Platykurtic). The Gumbel distribution in positively skewed with coefficients of skewness and excess kurtosis of 1.140 (highly skewed) and 2.40 (Platykurtic) respectively. The Frechet distribution is positively skewed with coefficients of skewness and excess kurtosis of 2.318 (highly skewed) and 12.77 (Leptokurtic) respectively. The Kolmogorov Smirnov (KS) test of goodness of fit results for the density of the Terminalia ivorensis is presented in Table 2.0. The test was made at $a=0.1,0.05,0.02$ and 0.01 levels of significance based on the hypothesis that, each of the five distribution models; Frechet, Gumbel maximum, Lognormal, Normal and Weibull distribution can be used to model the density of Terminalia ivorensis. 
Table 1: Laboratory test results for moisture content, density and bending test

\begin{tabular}{|c|c|c|c|c|}
\hline Specimen Mark & $\begin{array}{c}\text { Moisture Content } \\
(\%)\end{array}$ & Density $\left(\mathrm{kg} / \mathrm{m}^{3}\right)$ & $\begin{array}{l}\text { Bending Strength } \\
\left(\mathrm{N} / \mathrm{mm}^{2}\right)\end{array}$ & $\begin{array}{l}\text { Modulus of Elasticity } \\
\qquad\left(\mathrm{N} / \mathrm{mm}^{2}\right)\end{array}$ \\
\hline$A-1$ & 16.2 & 502.3 & 60.34 & 15955.23 \\
\hline$A-2$ & 14.2 & 356.4 & 78.36 & 14947.8 \\
\hline$A-3$ & 15.5 & 382.3 & 71.59 & 17830.7 \\
\hline$A-4$ & 12.1 & 514.2 & 59.70 & 19503.9 \\
\hline$A-5$ & 16.9 & 434.7 & 75.27 & 13752.1 \\
\hline$A-6$ & 12.3 & 499.0 & 102.76 & 12997.39 \\
\hline$A-7$ & 16.8 & 400.3 & 87.56 & 14227.94 \\
\hline$A-8$ & 21.4 & 415.5 & 81.32 & 22920.17 \\
\hline$A-9$ & 18.6 & 485.6 & 78.91 & 19904.82 \\
\hline$A-10$ & 20.4 & 577.7 & 92.52 & 18632.44 \\
\hline$A-11$ & 14.3 & 484.6 & 87.03 & 19904.8 \\
\hline$A-12$ & 19.9 & 489.1 & 88.61 & 20915.7 \\
\hline$A-13$ & 18.5 & 401.0 & 63.51 & 14947.8 \\
\hline$A-14$ & 15.8 & 413.3 & 70.14 & 9556.8 \\
\hline$A-15$ & 15.6 & 384.2 & 104.92 & 20915.7 \\
\hline$A-16$ & 24.0 & 390.9 & 97.71 & 13752.1 \\
\hline A-17 & 15.7 & 461.4 & 74.66 & 21717.51 \\
\hline$A-18$ & 17.1 & 536.8 & 89.92 & 15268.49 \\
\hline$A-19$ & 17.7 & 382.8 & 87.03 & 12448.35 \\
\hline$A-20$ & 17.5 & 453.6 & 105.66 & 14947.79 \\
\hline A-21 & 24.6 & 517.8 & 82.14 & 17095.1 \\
\hline$A-22$ & 25.8 & 322.7 & 90.38 & 13135.1 \\
\hline A-23 & 20.6 & 477.6 & 60.80 & 21717.5 \\
\hline A-24 & 25.2 & 347.4 & 71.14 & 14419.7 \\
\hline$A-25$ & 25.1 & 433.7 & 75.30 & 21351.5 \\
\hline A-26 & 16.5 & 447.0 & 76.25 & 15948.26 \\
\hline$A-27$ & 17.0 & 395.7 & 91.96 & 12997.39 \\
\hline A-28 & 16.2 & 470.6 & 64.74 & 18353.57 \\
\hline A-29 & 19.7 & 433.4 & 77.52 & 12833.55 \\
\hline A-30 & 16.0 & 525.9 & 51.95 & 15955.23 \\
\hline A-31 & 15.5 & 451.9 & 69.50 & 18022.4 \\
\hline A-32 & 19.7 & 610.1 & 76.94 & 12997.4 \\
\hline A-33 & 23.5 & 547.2 & 90.47 & 17830.7 \\
\hline A-34 & 18.6 & 406.3 & 97.21 & 16858.1 \\
\hline A-35 & 18.1 & 437.6 & 90.39 & 9781.60 \\
\hline A-36 & 13.7 & 456.7 & 72.75 & 8859.56 \\
\hline A-37 & 17.8 & 344.6 & 75.18 & 14227.94 \\
\hline A-38 & 9.4 & 316.7 & 87.11 & 16598.39 \\
\hline A-39 & 19.4 & 474.8 & 89.58 & 15704.24 \\
\hline$A-40$ & 11.6 & 514.4 & 93.08 & 17095.14 \\
\hline
\end{tabular}

As observed from the presented result, the critical values of the KS at the considered level of significance are all greater than the KS statistics for all the considered distribution models. Therefore, all the distribution can be considered as acceptable distribution models for density of Terminalia ivorensis.
However, looking at the KS statistics for all the five distributions, Normal distribution has the least KS statistics, followed by Weibull distribution, Lognormal, Gumbel maximum distribution, and then Frechet distribution in increasing order of KS statistics. The distribution models were ranked with the distribution 
model having the least KS statistics being ranked as 1 . Based on the results obtained, the Normal distribution is the best model for the density of Terminalia ivorensis.

\subsection{Bending Strength of Terminalia Ivorensis}

The mean and coefficient of variation for the Bending Strength of Terminalia ivorensis timber are $109.49 \mathrm{~N} / \mathrm{mm}^{2}$ and $16.09 \%$ respectively. The bending strength test data were also fitted to Normal, lognormal, gumbel, frechet and Weibull distribution models using the Kolmogorov Smirnov (KS) test.

From the normality test results the Weibull distribution was found to be negatively skewed to the left, with skewness values of -0.866 (moderately skewed) and excess kurtosis of 0.293 (platykurtic). The normal distribution has 0 skewness and 0 excess kurtosis (kurtosis equal to 3) as expected. The lognormal distribution is positively skewed with coefficients of skewness and excess kurtosis of 0.502 (moderately skewed) and 0.451 (platykurtic) respectively. The frechet distribution is positively skewed with coefficients of skewness and excess kurtosis of 2.53 (highly skewed) and 16.42 (Leptokurtic) respectively. The gumbel maximum distribution is also positively skewed with Skewness of 1.14 (highly skewed) and excess kurtosis of 2.40 (platykurtic).

The Kolmogorov smirnov (KS) test of goodness of fit results for the bending strength of the Terminalia ivorensis is presented in Table 3.0. The test was also made at $0.1,0.05,0.02$ and 0.01 level of significance considered based on the hypothesis that, each of the five distribution models; Frechet, Gumbel maximum, Lognormal, Normal and Weibull distribution can be used to model the bending strength of the Terminalia ivorensis. The critical values of the KS in table 2.0 at all the considered level of significance are all greater than the KS statistics for all the distribution models (Frechet, Gumbel maximum, Lognormal, Normal and the Weibull distributions) considered in this study.

Therefore, all the distribution can be considered as acceptable distribution models for bending strength of Terminalia ivorensis. However, looking at the KS statistics for all the five distributions, Weibull distribution has the least KS statistics, followed by Normal distribution, Lognormal, Gumbel maximum distribution, and then Frechet distribution in increasing order of KS statistics. The distribution models were ranked with the distribution model having the least KS statistics being ranked as 1 . Based on results obtained, the Weibull distribution is the best model for the bending strength of Terminalia ivorensis.

\subsection{Modulus of Elasticity of Terminalia Ivorensis}

The mean value and coefficient of variation of the modulus of elasticity of the tested Terminalia ivorensis timber are $16171.0 \mathrm{~N} / \mathrm{mm}^{2}$ and $21 \%$ respectively. The test data was fitted to Normal, Lognormal, Gumbel, Frechet and Weibull distribution models.

Table 2: Results of Kolmogorov Smirnov (KS) Test of Goodness of fit for the Density

\begin{tabular}{llllllll}
\hline \multirow{2}{*}{ S/No } & \multirow{2}{*}{ Distribution model } & $\alpha=0.1$ & $\alpha=0.05$ & $\alpha=0.02$ & $\alpha=0.01$ & \multirow{2}{*}{ KS } & \multirow{2}{*}{ Rank } \\
\cline { 3 - 5 } & & 0.1891 & 0.2101 & 0.2349 & 0.2521 & Statistics & \\
\hline 1 & Frechet & Accept & Accept & Accept & Accept & 0.152 & 5 \\
2 & Gumbel Maximum & Accept & Accept & Accept & Accept & 0.104 & 4 \\
3 & Lognormal & Accept & Accept & Accept & Accept & 0.070 & 3 \\
4 & Normal & Accept & Accept & Accept & Accept & 0.055 & 1 \\
5 & Weibull & Accept & Accept & Accept & Accept & 0.064 & 2 \\
\hline
\end{tabular}

Table 3: Results of Kolmogorov Smirnov (KS) Test of Goodness of fit for bending strength

\begin{tabular}{llllllll}
\hline S/No & Distribution model & $\alpha=0.1$ & $\alpha=0.05$ & $\alpha=0.02$ & $\alpha=0.01$ & KS & Rank \\
\cline { 3 - 5 } & & 0.1891 & 0.2101 & 0.2349 & 0.2521 & Statistics & \\
\hline 1 & Frechet & Accept & Accept & Accept & Accept & 0.179 & 5 \\
2 & Gumbel Maximum & Accept & Accept & Accept & Accept & 0.182 & 4 \\
3 & Lognormal & Accept & Accept & Accept & Accept & 0.146 & 3 \\
4 & Normal & Accept & Accept & Accept & Accept & 0.127 & 2 \\
5 & Weibull & Accept & Accept & Accept & Accept & 0.119 & 1 \\
\hline
\end{tabular}


Based on the Normality test conducted, the normal distribution has 0 skewness and 0 excess kurtosis (kurtosis equal to 3) as expected. The Lognormal distribution is positively skewed with Skewness of 0.691 (moderately skewed) and excess kurtosis of 0.861 (platykurtic). The Gumbel maximum distribution is positively skewed with coefficients of skewness and excess kurtosis of 1.140 (highly skewed) and 2.40 (platykurtic) respectively. The Weibull distribution is negatively skewed to the left, with skewness values of -0.275 (approximately symmetric) and excess kurtosis of -0.096 (platykurtic). The Frechet distribution is positively skewed with coefficients of skewness and excess kurtosis of 3.695 (highly skewed) and 53.053 (Leptokurtic) respectively.

The Kolmogorov smirnov (KS) test of goodness of fit results for modulus of elasticity of the Terminalia ivorensis is presented in Table 4.0. As for the density and bending strength, the test was made at $a=0.1$, $0.05,0.02$ and 0.01 levels of significance based on the hypothesis that, each of the five distribution models; Frechet, Gumbel maximum, Lognormal, Normal and Weibull distribution can be used to model the modulus of elasticity of Terminalia ivorensis. The critical values of the KS in Table 4 at all the considered level of significance are all greater than the KS statistics for all the distribution models (Frechet, Gumbel maximum, Lognormal, Normal and the Weibull distributions) considered in this study. Therefore, all the distribution can be considered as acceptable distribution models for modulus of elasticity of Terminalia ivorensis.

However, looking at the Kolmogorov Smirnov (KS) statistics for all the five distributions, lognormal distribution has the least KS statistics, followed by Normal distribution, Gumbel maximum, Weibull distribution, and then Frechet distribution in increasing order of KS statistics. The distribution models were ranked with the distribution model having the least KS statistics KS statistics being ranked as 1 . Based on the results obtained, the Lognormal distribution is also the best model for the modulus of elasticity of Terminalia ivorensis.

\subsection{Uncertainty Models}

The Eurocode 5 is a limit state design code in which the uncertainties in timber material properties and the applied loading are taken into account by the use of deterministic partial safety factors derived based on experience of building tradition. The best approach in accommodating uncertainties in structural design is to use reliability based design approach.

To perform reliability based structural design considering either ultimate or serviceability limit states, there is need to generate the uncertainty models 9mean, standard deviation, coefficient of variation and distribution models) for each of the variables that defined the material properties and loading.

The determined uncertainty models of the reference properties (density, bending strength and modulus of elasticity) of Terminalia ivorensis presented in sections 4.2 to 4.3 are presented in Table 5.

\subsection{Strength Class Allocation for the Terminalia ivorensis}

To use of a particular specie of timber in structures designed based on Eurocode 5, its strength class according to [1] strength classification system must be known.

Table 4: Results of Kolmogorov Smirnov (KS) Test of Goodness of fit for modulus of elasticity

\begin{tabular}{|c|c|c|c|c|c|c|c|}
\hline S/No & Distribution model & $\begin{array}{l}\alpha=0.1 \\
0.1891\end{array}$ & $\begin{array}{l}\alpha=0.05 \\
0.2101\end{array}$ & $\begin{array}{l}\alpha=0.02 \\
0.2349\end{array}$ & $\begin{array}{l}\alpha=0.01 \\
0.2521\end{array}$ & $\begin{array}{c}\mathrm{KS} \\
\text { Statistics }\end{array}$ & Rank \\
\hline 1 & Frechet & Accept & Accept & Accept & Accept & 0.1351 & 5 \\
\hline 2 & Gumbel Maximum & Accept & Accept & Accept & Accept & 0.0877 & 3 \\
\hline 3 & Lognormal & Accept & Accept & Accept & Accept & 0.0077 & 1 \\
\hline 4 & Normal & Accept & Accept & Accept & Accept & 0.0747 & 2 \\
\hline 5 & Weibull & Accept & Accept & Accept & Accept & 0.0890 & 4 \\
\hline
\end{tabular}

Table 5: Uncertainty models of the material properties of the Terminalia ivorensis

\begin{tabular}{lcccc}
\hline \multicolumn{1}{c}{ Material Properties } & Mean & $\begin{array}{c}\text { Standard } \\
\text { deviation }\end{array}$ & $\begin{array}{c}\text { Coefficient of variation } \\
(\%)\end{array}$ & $\begin{array}{c}\text { Distribution } \\
\text { models }\end{array}$ \\
\hline Density $\left(\mathrm{kg} / \mathrm{m}^{3}\right)$ & 449.24 & 68.40 & 15.16 & Normal \\
Bending strength $\left(\mathrm{N} / \mathrm{mm}^{2}\right)$ & 109.49 & 17.62 & 16.09 & Weibull \\
Modulus of elasticity $\left(\mathrm{N} / \mathrm{mm}^{2}\right)$ & 16171.0 & 3473.3 & 21.0 & Lognormal \\
\hline
\end{tabular}


The use of strength classes is intended to simplify the specification of timber, by grouping species in predefined categories. The classification is made using the characteristic values of the reference material properties of timber (bending strength, bending stiffness and density (are taken from bending strength, bending stiffness and density). The allocation to a strength class is governed by the lowest strength class applicable to one of these properties. In this study, the classification was made by considering the limiting values of the reference material properties from [1] as shown in Table 6. The measured values of the Terminalia ivorensis for bending strength, density and modulus of elasticity is as shown in Table 7.

Comparing the results presented in Table 7 with the limiting values of the [1] reference material properties in table 6.0 , it is clear that the mean value $\left(336.38 \mathrm{~kg} / \mathrm{m}^{3}\right)$ of the density on Terminalia ivorensis fall within the D18 strength class. Also, the characteristic value of the bending strength $\left(80.42 \mathrm{~N} / \mathrm{mm}^{2}\right)$ fall within D70 strength lass. Likewise, the mean value of elastic modulus $\left(16.17 \mathrm{kN} / \mathrm{mm}^{2}\right)$ fall within D18 strength class. However, since the D18 strength class is the least favourable, it implied that density and modulus of elasticity determined the strength class of Terminalia ivorensis. Therefore, the strength class of Terminalia ivorensis is D18.

\section{CONCLUSION}

In this paper, the uncertainty models (mean, coefficient of variation and probability distribution models) of the reference material properties (density, bending strength and modulus of elasticity) and the strength class of Nigeria grown Terminalia ivorensis (Black Afara) timber were presented. The mean values of the density, bending strength and modulus of elasticity are $449.24 \mathrm{~kg} / \mathrm{m}^{3}, 109.49 \mathrm{~N} / \mathrm{mm}^{2}$ and $16.17 \mathrm{kN} / \mathrm{mm}^{2}$ respectively. The corresponding coefficients of variation are $15.6 \% .16 .09 \%$ and $21.0 \%$. The probability distribution models obtained by fitting the various test results into some commonly used distribution models using Kolmogorov Smirnov test are Normal, Weibull and Lognormal distribution for density, bending strength and modulus of elasticity respectively. The Terminalia ivorensis timber tested in this study, was classified into D18 strength class based on [1] strength classification system.

Table 6: Limiting Values for Classification into Hardwood Classes [1]: Clause 5, Table 1)

\begin{tabular}{|c|c|c|c|c|}
\hline S/No. & Strength Class & $\begin{array}{c}\text { Limits of Characteristic } \\
\text { Bending Strength } \\
\left(\mathrm{N} / \mathrm{mm}^{2}\right)\end{array}$ & $\begin{array}{c}\text { Limits of } \\
\text { Characteristic } \\
\text { Density }\left(\mathrm{kg} / \mathrm{m}^{3}\right)\end{array}$ & $\begin{array}{l}\text { Limits of Mean } \\
\text { Modulus of Elasticity } \\
\left(\mathrm{kN} / \mathrm{mm}^{2}\right)\end{array}$ \\
\hline 1 & D18 & $f_{m, k} \leq 18$ & $\rho_{\mathrm{k}} \leq 475$ & $E_{\text {mean }} \leq 9.5$ \\
\hline 2 & D24 & $18<\mathrm{f}_{\mathrm{m}, \mathrm{k}} \leq 24$ & $475<\rho_{k} \leq 485$ & $9.5<\mathrm{E}_{\text {mean }} \leq 10$ \\
\hline 3 & D30 & $24<\mathrm{f}_{\mathrm{m}, \mathrm{k}} \leq 30$ & $485<\rho_{k} \leq 640$ & $9.5<\mathrm{E}_{\text {mean }} \leq 10$ \\
\hline 4 & D35 & $30<\mathrm{f}_{\mathrm{m}, \mathrm{k}} \leq 35$ & $640<\rho_{k} \leq 670$ & $9.5<E_{\text {mean }} \leq 10$ \\
\hline 5 & D40 & $35<\mathrm{f}_{\mathrm{m}, \mathrm{k}} \leq 40$ & $670<\rho_{k} \leq 700$ & $10<E_{\text {mean }} \leq 11$ \\
\hline 6 & D50 & $40<\mathrm{f}_{\mathrm{m}, \mathrm{k}} \leq 50$ & $700<\rho_{k} \leq 780$ & $11<\mathrm{E}_{\text {mean }} \leq 14$ \\
\hline 7 & D60 & $50<\mathrm{f}_{\mathrm{m}, \mathrm{k}} \leq 60$ & $780<\rho_{k} \leq 840$ & $14<E_{\text {mean }} \leq 17$ \\
\hline 8 & D70 & $70 \leq \mathrm{f}_{\mathrm{m}, \mathrm{k}}$ & $1080 \leq \rho_{k}$ & $20 \leq \mathrm{E}_{\text {mean }}$ \\
\hline
\end{tabular}

Table 7: Proposed Allocations of Strength Class for the Terminalia ivorensis

\begin{tabular}{|c|c|c|c|}
\hline \multirow{2}{*}{ Reference Material Properties } & \multicolumn{2}{|c|}{$12 \%$ Adjusted Values } & \multirow{2}{*}{$\begin{array}{l}\text { Allocated Strength Class (EN 338, } \\
\text { 2009) }\end{array}$} \\
\hline & Mean Values & Characteristic Values & \\
\hline Bending Strength $\left(\mathrm{N} / \mathrm{mm}^{2}\right)$ & 109.49 & 80.42 & \\
\hline Density $\left(\mathrm{kg} / \mathrm{m}^{3}\right)$ & 449.24 & 336.38 & D18 \\
\hline $\begin{array}{l}\text { Modulus of Elasticity } \\
\qquad\left(\mathrm{kN} / \mathrm{mm}^{2}\right)\end{array}$ & 16.17 & 10.44 & \\
\hline
\end{tabular}

\section{REFERENCES}

[1] EN 338. Structural Timber-Strength Classes. European Committee for Standardization. Austrian Standards Institute Heinestraße 38, 1020 Wien, 2009.
[2] Hassani, M. M., Falk K. W., Stefan H., and Hans J. H "Rheological Model for Wood", Computational Physics for Engineering Materials, Zurich, 2014. pp.1-37. 
[3] Shuaibu, A. A. (2010), Reliability Analysis of Simple Beam-Column Joint in Timber Portal Frame Based on Eurocode 5 Design Requirements, an Unpublished Undergraduate Project, Submitted to the Civil Engineering Department Ahmadu Bello University, Zaria, Nigeria.

[4] NCP 2. Nigerian Standard Code of Practice, NCP 2: Grade stresses for Nigerian Timbers. Nigerian Standard Organization, Federal Ministry of Industries, Lagos, Nigeria, 1973.

[5] CP 112. The Structural use of Timber; British Code of Practice. British Standard Institution London, 1967.

[6] BS 5268: Part 2. Code of Practice for Permissible Stress Design, Material and Workmanship, British Standards Institution, London, 2002.

[7] Eurocode 5: Design of Timber Structures - Part 11: General Common Rules for Buildings. CSI, Prague, December 2006.

[8] Chanakya, A. Design of Structural Elements. Concrete, Stee/work, Masonry and Timber Design to British Standards and Eurocodes. $3^{\text {rd }}$ Ed. Taylor and Francis, USA, 2009.

[9] Porteous, J. and Kermani A. Structural Timber Design to Eurocode 5, Blackwell Publishing Company, Oxford, U.K, 2007.

[10] Robert, H. Timber Frame Houses. Design Principles. Centre for Timber Engineering, Edingburk, Napier University. 10 Colinton Road Edingburg EH10. United Kingdom, 2009.

[11] Dorina, I., Oana, S., and Iulian, A. "Analysis of Wood Bending Properties on Standardized Samples and Structural Size Beams Tests". BULETINUL Institutului Politehnic Din Iaşi Publicat de Universitatea Tehnică "Gheorghe Asachi" Din IaşiTomul. Secţia Constructii. Arhitectură. Vol. 1, 2012, pp $65-75$.

[12] Bartunkova, E. "Constitutive Model of Timber" A Master Thesis submitted to Faculty of Civil Engineering Department of Mechanics Czech Technical University, Prague, 2012, Pp.1-30.

[13] Wiedenhoef, A. Structure and Functions of Wood, Chapter 3, Wood handbook Wood as an Engineering Material, General Technical Report FPL GTR-190, Department of Agriculture, Forest Service, Forest Products Laboratory, Madison, WI: U.S, 2010.

[14] Kohler, J. Reliability of Timber Structures, Institute of Structural Engineering, Swiss Federal Institute of Technology, Zurich. Pp.1-3. 2000.
[15] Holzer, S. M, Joseph R. L, and David A. Dillard A. D. A Review of Creep in Wood: Concepts Relevant to Develop Long-term Behavior Predictions for Wood Structures. Wood and Fiber Science, 1989, 21(4):376-392.

[16] Liu T. Creep of Wood Under a Large Span of Loads In Constant and Varying Environments Part 1: Experimental Observations and Analysis. Holzals Roh- und Werksto, 51(6) 1993: pp. $400-$ 405.

[17] Houska, M. and Bucar B. Mechano-sorptive Behavior of Different Categories of Spruce Wood. In Proceedings of the 1st International Conference on Mechanics of Time Dependent Materials, Society for experimental mechanics, Bethel. 1995, pp. 173-178.

[18] Bengtsson, C. "Mechano-Sorptive Creep of Wood in Tension and Compression". $1^{\text {st }}$ RILEM Symposium on Timber Engineering, Stockholm, 13 - 14 September, 1999, pp. 317-326.

[19] Hanhijarvi, A. Computational Method for Predicting the Long-Term Performance of Timber Beams in Variable Climates. Materials and Structures, Vol. 33(226), 2000. pp. 127-134.

[20] EN 408. European Standard: Timber structures Structural Timber - Determination of Some Physical and Mechanical Properties. 2004, Comité Européen de Normalisation, Brussels, Belgium, 2004.

[21] Martin, C. Tropical Timber of the World, Agriculture Handbook. No. 607. Department of Agriculture, United States, 1984.

[22] Cirad. Tropix-African Wood. "Production and Processing of Tropical Wood" Research Unit Centre de cooperation international en research agronomique pour le Development Cirad, Forestry Department, 2009.

[23] Aigbe, H. I., Modugu, W. W., and Oyebade, B. A., "Modeling Volume from Stump Diameterof Terminalia ivorensis in Sokponba Forest Researve, Edo State". Nigeria. ARPN Journal of Agricultural and Biological Science. Vol. (3), 2012, pp 146-148.

[24] EN 384. Timber Structures; Structural timber Determination of characteristic values of mechanical properties and density. Comité Européen de Normalisation, Brussels, Belgium, 2004.

[25] EN 13153-1. Moisture Content of a Piece of Sawn Timber-Part 1. Determination by Oven Dry Method. European Committee for Standardization. Austrian Standards Institute Heinestraße 38, 1020 Wien, 2002. 